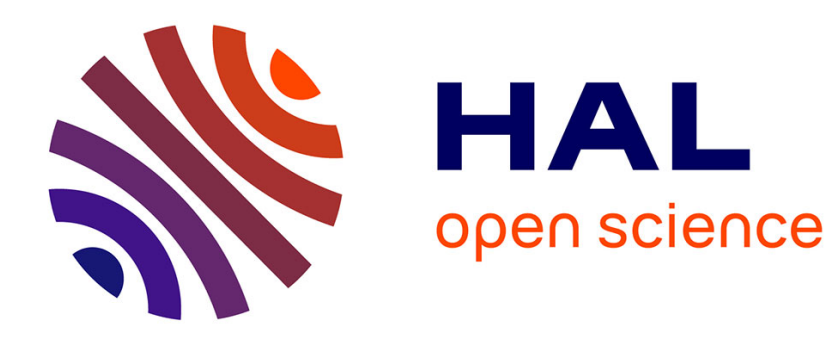

\title{
Effect of dependency in systems for multivariate surveillance
}

\author{
Eva Andersson
}

\section{To cite this version:}

Eva Andersson. Effect of dependency in systems for multivariate surveillance. Communications in Statistics - Simulation and Computation, 2009, 38 (03), pp.454-472. 10.1080/03610910802531307. hal-00514340

\section{HAL Id: hal-00514340 \\ https://hal.science/hal-00514340}

Submitted on 2 Sep 2010

HAL is a multi-disciplinary open access archive for the deposit and dissemination of scientific research documents, whether they are published or not. The documents may come from teaching and research institutions in France or abroad, or from public or private research centers.
L'archive ouverte pluridisciplinaire HAL, est destinée au dépôt et à la diffusion de documents scientifiques de niveau recherche, publiés ou non, émanant des établissements d'enseignement et de recherche français ou étrangers, des laboratoires publics ou privés. 


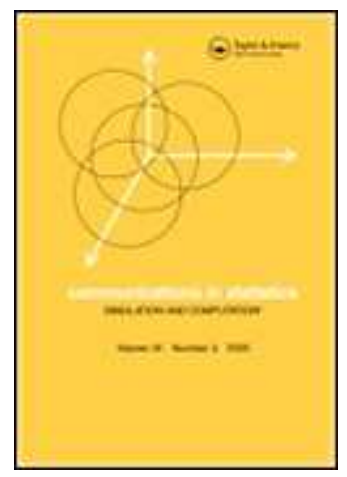

\section{Effect of dependency in systems for multivariate surveillance}

\begin{tabular}{|c|c|}
\hline Journal: & Communications in Statistics - Simulation and Computation \\
\hline Manuscript ID: & LSSP-2008-0149.R1 \\
\hline Manuscript Type: & Original Paper \\
\hline $\begin{array}{r}\text { Date Submitted by the } \\
\text { Author: }\end{array}$ & 13-Sep-2008 \\
\hline Complete List of Authors: & $\begin{array}{l}\text { Andersson, Eva; Statistical research unit, Goteborg University and } \\
\text { Department of Occupational and Environmental medicine, Goteborg } \\
\text { University }\end{array}$ \\
\hline Keywords: & surveillance, multivariate, likelihood ratio, optimal, dependency \\
\hline Abstract: & $\begin{array}{l}\text { Systems for multivariate on-line surveillance (e.g. outbreak } \\
\text { detection), are investigated. Optimal systems for statistical } \\
\text { surveillance are based on likelihood ratios. Three systems are } \\
\text { compared; based on each marginal density, based on the joint } \\
\text { density and based on the Hotelling's T2. The effect of dependency } \\
\text { between the monitored processes is investigated, and the effect of } \\
\text { correlation between the change times. When the first change occurs } \\
\text { immediately, the three methods give similar delay of an alarm, in } \\
\text { the situation with independency. For late changes, T2 has the } \\
\text { longest delay, both for independent processes and for processes } \\
\text { with a positive covariance. }\end{array}$ \\
\hline
\end{tabular}

\section{S ScholaroNE \\ Manuscript Central}




\title{
Effect of dependency in systems for multivariate surveillance
}

\author{
E Andersson \\ Statistical Research Unit, Göteborg University, Sweden \\ Dep of Occupational and Environmental medicine, Sahlgrenska University Hospital, \\ Göteborg, Sweden \\ Corresponding author: E Andersson \\ Short title: Dependency in multivariate on-line surveillance
}

\begin{abstract}
Systems for multivariate on-line surveillance (e.g. outbreak detection), are investigated. Optimal systems for statistical surveillance are based on likelihood ratios. Three systems are compared; based on each marginal density, based on the joint density and based on the Hotelling's T2. The effect of dependency between the monitored processes is investigated, and the effect of correlation between the change times. When the first change occurs immediately, the three methods give similar delay of an alarm, in the situation with independency. For late changes, T2 has the longest delay, both for independent processes and for processes with a positive covariance.

Keywords: Surveillance; Multivariate; Likelihood ratio; Optimal; Dependency.
\end{abstract}

\section{Introduction}

In many situations it is important to monitor a process in order to detect an important change as soon as possible. Examples are turning point detection in business cycles 
(Neftci (1982), Hamilton (1989), Andersson, et al. (2004)), in hormone cycles (Royston (1991)), in influenza cycles (Baron (2002)) and in financial cycles (Frisén (2007), Bock (2008)). Other areas are detection of growth retardation of foetuses (Petzold, et al. (2004)) or monitoring of prematurely born children (Löfqvist, et al. (2006)). Yet another is detection of an increased level, emerging from a source and spreading spatially (Järpe (1999)). On-line monitoring is based on repeated decisions: at each time point, a new observation becomes available and a new decision is made as to whether the process has changed or nor. The methodology of statistical surveillance is appropriate.

Statistical surveillance is a methodology for discriminating between two events, "the change has occurred" and "the change has not occurred". The time of change is unknown. The time scale can differ between applications (days, weeks, months), but common to all surveillance are the repeated decisions, made at each time point. The decision is made using an alarm statistic and an alarm limit. In industrial quality control charts (e.g. xbarcharts), an alarm can be given as soon as an observation crosses the alarm limit (Shewhart (1931)). There is always a risk for a false alarm, but the parameters of the surveillance method are chosen so that we know the false alarm property. For motivated alarms, i.e. when the change actually happens, we want a quick detection. Since we have repeated decisions, size and power are not appropriate measures. Instead we have a tradeoff between false alarms and the delay of a motivated alarm. The false alarms can be controlled by a fixed average run length, $\mathrm{ARL}^{0}$. Besides the Shewhart method, the EWMA method (Roberts (1959)) and the CUSUM method (Page (1954)) can be mentioned. 
In many situations we monitor several processes, which may change simultaneously or at different times. One example is business cycle monitoring, where changes in the import and export series probably can be seen before changes in unemployment, but where all these series measure the underlying business cycle. There are different approaches in multivariate monitoring: the data can be reduced to a scalar at each time or we can use separate alarm systems for each process in combination with an inference rule like union intersection. Also, multivariate versions of univariate methods have been suggested, for example MEWMA and MCUSUM. Important aspects are the correlation between the change times and the dependency between the processes themselves.

The aim of this paper is to compare different multivariate surveillance systems. In Section 3, optimality in surveillance is discussed and in Section 4 some of the different approaches to multivariate surveillance are reviewed. In Section 5 the results of a simulation study are presented and Section 6 contains a discussion.

\section{Model}

In this paper we study the situation when two processes may change at different time points $\left(\tau_{X}\right.$ and $\left.\tau_{Y}\right)$ and where the $\tau:$ s can be dependent.

The aim is to detect an increase in the expected value. With two series, we want to detect the first change (the first increase). The observations (X, Y), up to decision time s, are modeled according to

$$
\left(\begin{array}{c}
m(1) \\
m(2) \\
\ldots \\
m(s)
\end{array}\right)=\left(\begin{array}{cc}
x(1) & y(1) \\
x(2) & y(2) \\
\ldots & \ldots \\
x(s) & y(s)
\end{array}\right)=\left(\begin{array}{cc}
\mu_{X}(1) & \mu_{Y}(1) \\
\mu_{X}(2) & \mu_{Y}(2) \\
\ldots & \ldots \\
\mu_{X}(s) & \mu_{Y}(s)
\end{array}\right)+\left(\begin{array}{cc}
\varepsilon_{X}(1) & \varepsilon_{Y}(1) \\
\varepsilon_{X}(2) & \varepsilon_{Y}(2) \\
\ldots & \ldots \\
\varepsilon_{X}(s) & \varepsilon_{Y}(s)
\end{array}\right)
$$


The stochastic term at time $\mathrm{t},\left(\varepsilon_{X}(t) \varepsilon_{Y}(t)\right)$, follows a bivariate normal distribution, with expected value zero and covariance matrix

$$
\sigma^{2}\left(\begin{array}{ll}
1 & \rho \\
\rho & 1
\end{array}\right)
$$

where $\rho=$ correlation between $X(t)$ and $Y(t)$.

The variables $\mathrm{X}(\mathrm{t})$ and $\mathrm{Y}(\mathrm{t})$ are (possibly) dependent but not $\mathrm{X}(\mathrm{t})$ and $\mathrm{X}(\mathrm{t}-\mathrm{j}), \mathrm{Y}(\mathrm{t})$ and $\mathrm{Y}(\mathrm{t}-\mathrm{j})$ or $\mathrm{X}(\mathrm{t})$ and $\mathrm{Y}(\mathrm{t}-\mathrm{j})$. Surveillance of processes with autocorrelation is treated in Frisén and Sonesson (2005), Petzold, et al. (2004), Knoth and Schmid (2004) and Okhrin and Schmid (2007). The aim is to detect the first change in either of the $\mu$ vectors $\left(\mu_{X}\right.$ and $\mu_{Y}$ ). One application might be detection of the start of an influenza epidemic (an increase from a constant base line). The Swedish institute for infectious disease control receives weekly information about confirmed cases (laboratory diagnosed) and suspected cases. The development is roughly captured through the following parametric model for $\mu$, which will be used for both $\mathrm{X}$ and $\mathrm{Y}$ in a simulation study below.

$$
\mu(t): \begin{cases}\mu^{\mathrm{D}}(\mathrm{t}): \beta_{01}, & \mathrm{t}<\tau \\ \mu^{\mathrm{C} \tau}(\mathrm{t}): \beta_{02}+\beta_{1} \cdot(\mathrm{t}+1-\tau)+\beta_{2} \cdot(\mathrm{t}+1-\tau)^{3}, & \mathrm{t} \geq \tau\end{cases}
$$

where $\beta_{1}<0, \beta_{2}>0$. Thus, for $\tau_{X}=\tau_{Y}, X$ and $Y$ have the same distribution and they are independent (or dependent) conditional on $\tau$. The model above might be too crude in a real situation, but is used here to demonstrate the inferential aspects of multivariate surveillance.

A bivariate Geometric distribution is used for $\left(\tau_{X}, \tau_{Y}\right)$, with parameters $\left(v_{01}, v_{10}, v_{11}\right)$. The marginal distributions are $\tau_{\mathrm{X}} \sim \operatorname{Geo}\left(v_{1 .}=v_{10}+v_{11}\right)$ and $\tau_{\mathrm{Y}} \sim \operatorname{Geo}\left(v_{.1}=v_{01}+v_{11}\right)$. The two marginal intensities are assumed to be equal $\left(v_{1}=v_{.1}=0.10\right)$. The value of $v_{11}$ will be 
varied, thereby yielding different correlations, here $\{0,0.80\}$. The correlation between $\tau_{X}$ and $\tau_{\mathrm{Y}}$ is hence forward denoted $\psi$.

\section{Optimality and evaluation of multivariate surveillance}

Statistical surveillance is a methodology for discriminating between the two events, namely $\mathrm{C}=$ "the change has occurred" and $\mathrm{D}=$ "the change has not occurred". By an alarm system we decide whether $\mathrm{D}$ or $\mathrm{C}$ is the most likely.

Statistical surveillance is used for on-line detection of an important change in the underlying process, for instance a change in the expected value. For e.g. daily data, a new decision is made each day, based on the available data. When there is enough evidence of a change, an alarm is called. The alarm limit in the surveillance system is set so that the alarm system yields a specified false alarm risk.

In univariate surveillance we observe the process $X$ at each decision time $s=1,2, \ldots$ At time $s$ the vector of available observations is denoted $x_{s}=\{x(1), x(2), \ldots, x(s)\}$. At an unknown time, $\tau$, there is a change in the distribution of $X$, so that

$$
X(s) \square\left\{\begin{array}{l}
f(x(s) \mid D), s<\tau \\
f(x(s) \mid C), s \geq \tau
\end{array}\right.
$$

The events $\mathrm{D}$ and $\mathrm{C}$ are specified according to the change of interest (a simple case is a change in the mean, from $\mu 0$ to $\mu 1)$. In a multivariate situation the aim is often to detect the first change in any of the $\mathrm{p}$ monitored processes, $\tau_{(1)}=\min \left[\tau_{1}, \ldots \tau_{\mathrm{p}}\right]$.

The time of alarm, $t_{\mathrm{A}}$, is defined as the first time that the alarm statistic exceeds the alarm limit. The alarm limit is set so that the false alarm property has a specified value. In quality control, it is common to use the average run length to the first false alarm, $\mathrm{ARL}^{0}=\mathrm{E}\left[\mathrm{t}_{\mathrm{A}} \mid \tau=\infty\right]$. Sometimes the median run length is used, $\mathrm{MRL}^{0}$, instead of the 
arithmetic mean. In multivariate surveillance, the false discovery rate can be used (see e.g. Wong, et al. (2003)). In many theoretical work (e.g. Shiryaev (1963)), the false alarm probability is used, which summarize the false alarm distribution using the distribution of $\tau$, such that

$$
\mathrm{PFA}=\sum_{i=1}^{\infty} P\left(t_{A}<i\right) \cdot P(\tau=i)
$$

For an on-line system, the ability to detect a change quickly is important, i.e. a short delay for motivated alarms. For most surveillance methods, the delay of an alarm depends on when the change does occur, in relation to the start of the surveillance. The delay is often longest when the change occurs at the start $(\tau=1)$. The conditional expected delay of an alarm (see Frisén and Wessman (1999)) is defined as

$$
\mathrm{CED}(\mathrm{t})=E\left[t_{A}-\tau \mid t_{A} \geq \tau, \tau=t\right]
$$

Many evaluations are made using $\tau=1$, e.g $\operatorname{CED}(1)$ which is equivalent to $\mathrm{ARL}^{1}-1$. However it is important to consider other change point times also. In multivariate surveillance regarding the first change, $\tau_{(1)}$, the following delay measure has been suggested (Wessman (1999))

$$
\operatorname{CED}\left(\mathrm{t}_{1}, \mathrm{t}_{2}\right)=\mathrm{E}\left[\mathrm{t}_{\mathrm{A}}-\tau_{(1)} \mid \mathrm{t}_{\mathrm{A}} \geq \tau_{(1)}, \tau_{\mathrm{X}}=\mathrm{t}_{1}, \tau_{\mathrm{Y}}=\mathrm{t}_{2}\right]
$$

Optimal alarm systems are based on the full likelihood ratio between C and D (Shiryaev (1963), Frisén and de Maré (1991)),

$$
\frac{f\left(x_{s} \mid C\right)}{f\left(x_{s} \mid D\right)},
$$

where $\mathrm{x}_{\mathrm{s}}=\{\mathrm{x}(1), \mathrm{x}(2), \ldots, \mathrm{x}(\mathrm{s})\}$. The full likelihood ratio minimizes the expected delay for a fixed false alarm probability (Frisén (2003)). Optimality is further discussed in Section 
4.1.3. If we want to detect a change at the current time s, then $C=\{\tau=s\}, D=\{\tau>s\}$ When the observations are independent and normally distributed, then the optimal full likelihood ratio reduces to the last observation, $\mathrm{x}(\mathrm{s})$.

$$
\frac{f\left(x_{s} \mid \tau=s\right)}{f\left(x_{s} \mid \tau>s\right)}=\frac{f(x(1) \mid \tau=s) \cdot f(x(2) \mid \tau=s) \cdot \ldots \cdot f(x(s) \mid \tau=s)}{f(x(1) \mid \tau>s) \cdot f(x(2) \mid \tau>s) \cdot \ldots \cdot f(x(s) \mid \tau>s)}=\frac{f(x(s) \mid \tau=s)}{f(x(s) \mid \tau>s)}
$$

This is the Shewhart method, used in e.g. an xbar-chart. Contrary to using only the latest observation, the CUSUM and EWMA methods cumulate the observations. CUSUM is the maximum of the likelihood ratios at the decision time s. The EWMA method uses an exponentially weighted moving average and for certain values of the smoothing constant, EWMA is approximately the same as LR (Frisén and Sonesson (2006)).

When it is important to detect if there has been a change since the start of the surveillance, we specify $C=\{\tau \leq s\}=\{\{\tau=1\},\{\tau=2\}, \ldots,\{\tau=s\}\}$ and $D=\{\tau>s\}$. Then the full likelihood ratio consists of s components

$$
w_{1} \frac{f\left(x_{S} \mid \tau=1\right)}{f\left(x_{s} \mid \tau>s\right)}+w_{2} \frac{f\left(x_{S} \mid \tau=2\right)}{f\left(x_{s} \mid \tau>s\right)}+\ldots+w_{s} \frac{f\left(x_{S} \mid \tau=s\right)}{f\left(x_{s} \mid \tau>s\right)}>k_{s}
$$

where $\mathrm{w}_{\mathrm{i}}=\mathrm{P}(\tau=\mathrm{i}) / \mathrm{P}(\tau \leq \mathrm{s})$ and $\mathrm{k}_{\mathrm{s}}=\mathrm{k} \cdot \mathrm{P}(\tau \geq \mathrm{s}) / \mathrm{P}(\tau<\mathrm{s})$. Contrary to $\mathrm{C}=\{\tau=\mathrm{s}\}$ we now consider a composite event $\mathrm{C}=\{\tau \leq \mathrm{s}\}$ and the full likelihood ratio will include all observations $\{x(1), \ldots, x(s)\}$. Here it is optimal to use all observations in the sense that the expected delay is minimized.

When $\mathrm{P}(\mathrm{C})=1-\mathrm{P}(\mathrm{D})$, the likelihood ratio is equivalent to using the posterior probability (alarm when $P\left(C \mid x_{s}\right)>k$ ). This is often used in hidden Markov model approaches (HMM), see e.g. Koskinen and Öller (2004).

URL: http://mc.manuscriptcentral.com/lssp E-mail: comstat@univmail.cis.mcmaster.ca 


\section{Methods}

\subsection{Different approaches to multivariate surveillance}

In a multivariate setting there are p processes $\left\{X_{1}, X_{2}, \ldots, X_{p}\right\}$ for which

$$
X_{j}(s) \square\left\{\begin{array}{l}
f\left(x_{j}(s) \mid D\right), s<\tau_{j} \\
f\left(x_{j}(s) \mid C\right), s \geq \tau_{j}
\end{array} .\right.
$$

An overview of multivariate surveillance is given in Sonesson and Frisén (2005), who categorize different approaches to multivariate surveillance; reduction of dimensionality, reduction to one scalar statistic, parallel surveillance, vector accumulation and simultaneous solution. In this paper we compare reduction to scalar, parallel surveillance and simultaneous solution.

\subsubsection{Reduction to one scalar statistic at each time}

The $\mathrm{p}$ X-processes can be reduced to a scalar at each time, for example by a (weighted) mean. Wessman (1998) showed that when the processes have identical change times $\left(\tau_{1}=\tau_{2}=\ldots=\tau_{p}=\tau\right)$, there exists a sufficient univariate reduction of the variables $\left\{X_{1}, \ldots\right.$, $\left.X_{p}\right\}$. Thus, without loss of information, the multivariate data can be reduced to a scalar statistic and then univariate surveillance can be applied. The sufficiency also holds when the changes times are not identical but the lag times between them are known.

When the changes occur at different time points, a problem with a reduction is to determine which variable that caused the alarm. Javaheri and Houshmand (2001) suggest a follow-up with discriminant an lysis. Jolayemi (2000) constructs multiple control regions for two assignable causes. Mason, et al. (1995) decompose T2 into independent components, each reflecting an individual variable $\mathrm{Xj}$. 
Wikström, et al. (1998) use principal component analysis to derive the most important principal components and then univariate CUSUM and univariate EWMA is applied.

Abu-Shawiesh and Abdullah (2001) study surveillance of two correlated processes where both scale and location change. The T2 statistic is based on robust estimates of location and scale. This approach is compared to the ordinary T2. Mason, et al. (2003) find that AR processes result in a U-shaped T2 curve.

Another reduction is to use the minimum and maximum values at each time, as is done in Sepúlveda and Nachlas (1997). Kang and Albin (2000) model the variable Y as a function of the variable $\mathrm{X}$ and monitor the slope and intercept by $\mathrm{T} 2$ statistic as well as the residuals (deviations from reference line).

Aparisi, et al. (2001) reduce the covariance matrix through the determinant or the trace. This scalar is monitored, using univariate Shewhart, EWMA and CUSUM. Guerrero-Cusumano (1995) uses an entropy measure instead of the determinant.

Stoumbos and Jones (2000) reduce the multivariate data to a probability measure which shows how "central" the observation is.

Lu, et al. (1998) study correlated variables and the proportion of non-conforming units. The multivariate data are reduced to a scalar by weighting together the nonconforming units and then monitored by univariate Shewhart.

Cheng and Liu (2000) use a rank measure for how outlying an observation is and then the univariate rank variable is monitored using a Shewhart approach.

Koskinen and Öller (2004) suggest the use of a weighted index, which is monitored using univariate methods. A similar approach is used in Talluri and Sarkis (2002). 
Qiu and Hawkins (2001) use the anti-ranks of the p observations at each time and summarize the anti ranks in a statistic which is monitored using univariate CUSUM.

There are several suggested methods which are a multivariate variation of a univariate method, such as MEWMA and MCUSUM. Crosier (1988) and Pignatiello and Runger (1990) used an MCUSUM on the same form as as the univariate CUSUM, only with matrixes instead of scalars.

Bodden and Rigdon (1999) use a multivariate EWMA and smooth all p processes using the same constant, $\lambda$, and then the vector of the smoothed values is reduced by the T2 statistic. This approach is also used in Love and Linderman (2003) and Molnau, et al. (2001) and by Stoumbos and Sullivan (2002), who show that if the smoothing constant equals 1 (no smoothing) and the process is not normally distributed, then the $\mathrm{ARL}^{0}$ is over estimated if the alarm limits are determined under normality assumptions. But for a small smoothing constant, the $\mathrm{ARL}^{0}$ is not so biased, even if the normality assumption is violated. A small smoothing constant gives approximately equal weight to all observations, which is approximately normal according to the central limit theorem.

Lowry, et al. (1992) use EWMA smoothing with separate $\lambda$ values, and then reduction by the T2 statistic. The $\lambda$ values are determined so as to minimize the ARL1. Yumin (1996) suggests that if the $X$ processes are correlated, they should be transformed into principal components, which are then smoothed separately. Runger, et al. (1999) reduce the dimension by a transform similar to principal component analysis, then the transformations are smoothed using the same $\lambda$ and then the T2 statistic is calculated from the smoothed series. Gan (1997) constructs a control chart with the smoothed variance on one axis and the smoothed mean on the other, called a combined EWMA 
chart. The advantage, to a $\mathrm{T} 2$ reduction, is that the chart shows whether it is the mean or the variance that is out-of control.

Hawkins (1991) applied a univariate CUSUM to a linear combination of the variables $\left\{X_{1}, X_{2}, \ldots, X_{p}\right\}$. Wessman (1998) showed that if the p processes have identical change times, then data can, without loss of information, be reduced to a univariate index.

\subsubsection{Parallel surveillance}

The marginal density of each process can be monitored. One drawback is that no information about the dependency structure is used. The surveillance system for $\mathrm{X}_{1}$ is only concerned with $\tau_{1}$, and correspondingly for $X_{2}, X_{3}$ etc. For process $X_{j}$ at time s, we have alarm statistic $\mathrm{p}\left(\mathrm{x}_{\mathrm{js}}\right)$ and alarm limit $\mathrm{k}_{\mathrm{s}}^{\mathrm{j}}$. An alarm is called when $\mathrm{p}\left(\mathrm{x}_{\mathrm{js}}\right)>\mathrm{k}_{\mathrm{s}}^{\mathrm{j}}$, where $x_{j s}=\left\{x_{j}(1), x_{j}(2), \ldots, x_{j}(s)\right\}$

The time of alarm of $X_{j}$ is

$$
t_{\mathrm{Aj}}=\min \mathrm{t}: \mathrm{p}\left(\mathrm{x}_{\mathrm{jt}}\right)>\mathrm{k}_{\mathrm{t}}^{\mathrm{j}}
$$

The time of alarm for the whole system is defined as

$$
\mathrm{t}_{\mathrm{A}}=\min \left\{\mathrm{t}_{\mathrm{A} 1}, \mathrm{t}_{\mathrm{A} 2}, \ldots, \mathrm{t}_{\mathrm{Ap}}\right\}
$$

Does, et al. (1999) uses separate surveillance for of each process (each principal component) in a case study. In Woodall and Ncube (1985) a univariate CUSUM is used for each of the p processes.

\subsubsection{Simultaneous solution}

In a simultaneous solution, the joint distribution of the p processes can be used. Shiryaev (1963) showed that the likelihood ratio between C and D is optimal in the sense that is maximized the expected utility, $\mathrm{E}[\mathrm{u}]$, where $\mathrm{u}$ equals 


$$
\mathrm{u}\left(\mathrm{t}_{\mathrm{A}}, \tau\right)= \begin{cases}\mathrm{h}\left(\mathrm{t}_{\mathrm{A}}-\tau\right) \quad, \mathrm{t}_{\mathrm{A}}<\tau \\ \mathrm{a}_{1} \cdot\left(\mathrm{t}_{\mathrm{A}}-\tau\right)+\mathrm{a}_{2}, \mathrm{t}_{\mathrm{A}} \geq \tau\end{cases}
$$

The optimality was proven for the situation when $\tau$ follows a Geometric distribution (with parameter $v$ ). If the function $h\left(t_{A}-\tau\right)$ is a constant, $b$, the utility is maximized when the delay, $\mathrm{t}_{\mathrm{A}}-\tau$, is minimized (Frisén (2003)). The minimal expected delay was shown to hold also for a situation where $\tau$ is not Geometrically distributed (Andersson (2004)).

Here we study the situation when we want to detect the first change, $\tau_{(1)}=\min \left[\tau_{1}, \tau_{2}\right.$, $\left.\ldots, \tau_{\mathrm{p}}\right]$ and then the utility can be written as

$$
\mathrm{u}\left(\mathrm{t}_{\mathrm{A}}, \tau_{(1)}\right)=\left\{\begin{array}{l}
\mathrm{h}\left(\mathrm{t}_{\mathrm{A}}-\tau_{(1)}\right), \mathrm{t}_{\mathrm{A}}<\tau_{(1)} \\
\mathrm{a}_{1} \cdot\left(\mathrm{t}_{\mathrm{A}}-\tau_{(1)}\right)+\mathrm{a}_{2}, \mathrm{t}_{\mathrm{A}} \geq \tau_{(1)}
\end{array}\right.
$$

where $t_{A}$ is the time of alarm for the whole system (e.g. (4)). The distribution of $\tau_{(1)}$ depends on the $\mathrm{p}$-variate distribution for $\left(\tau_{1}, \ldots, \tau_{\mathrm{p}}\right)$. For $\mathrm{p}=2$, we use the bivariate Geometric distribution, see e.g. Marshall and Olkin (1997). Then $\tau_{(1)}$ follows a Geometric distribution (Sun and Basu (1995)) and the optimality holds: the likelihood ratio maximizes the expected utility.

Wessman (1999) investigated the situation where $C=\left\{\tau_{(1)}=s\right\}$. In this paper we investigate $\mathrm{C}=\left\{\tau_{(1)} \leq \mathrm{s}\right\}=\left\{\left\{\tau_{(1)}=1\right\}, \ldots,\left\{\tau_{(1)}=\mathrm{s}\right\}\right\}$. The $\mathrm{D}$ event is specified as $\left\{\tau_{(1)}>\mathrm{s}\right\}$. Below the optimal surveillance system is derived from the likelihood ratio. Since $\mathrm{P}(\mathrm{C})=$ 1-P(D), the likelihood ratio is equivalent to the posterior probaility

$$
P\left(C \mid m_{s}\right)=P\left(m_{s} \cap C\right) /\left(P\left(m_{s} \cap C\right)+P\left(m_{s} \cap D\right)\right)>k,
$$

where $\mathrm{m}_{\mathrm{s}}=\{\mathrm{m}(1), \ldots, \mathrm{m}(\mathrm{s})\}=\left\{\left\{\mathrm{x}_{1}(1), \ldots, \mathrm{x}_{\mathrm{p}}(1)\right\}, \ldots,\left\{\mathrm{x}_{1}(\mathrm{~s}) \ldots, \mathrm{x}_{\mathrm{p}}(\mathrm{s})\right\}\right\}$ and $\mathrm{k}$ is a constant limit. 
Hence forward we express the likelihood function by $\mathrm{f}\left({ }^{*}\right)$ instead of $\mathrm{P}(*)$, so that

$$
\frac{f\left(m_{s} \cap C\right)}{f\left(m_{s} \cap D\right)}>\frac{k}{1-k}
$$

For $C=\left\{\tau_{(1)} \leq s\right\}$ and $D=\left\{\tau_{(1)}>s\right\}$, the likelihood ratio equals

$$
\sum_{t=1}^{s} w_{s}^{t} \cdot L(s, t)=w_{s}^{1} \cdot \frac{f\left(m_{s} \mid \tau_{(1)}=1\right)}{f\left(m_{s} \mid \tau_{(1)}>s\right)}+w_{s}^{2} \cdot \frac{f\left(m_{s} \mid \tau_{(1)}=2\right)}{f\left(m_{s} \mid \tau_{(1)}>s\right)}+\ldots+w_{s}^{s} \cdot \frac{f\left(m_{s} \mid \tau_{(1)}=s\right)}{f\left(m_{s} \mid \tau_{(1)}>s\right)}>\mathrm{k}_{\mathrm{s}} .
$$

The weights, $\mathrm{w}_{\mathrm{s}}^{\mathrm{t}}=\mathrm{P}\left(\tau_{(1)}=\mathrm{t}\right) / \mathrm{P}\left(\tau_{(1)} \leq \mathrm{s}\right)$, and the limit, $\mathrm{k}_{\mathrm{s}}=\mathrm{k}^{\prime} \cdot \mathrm{P}\left(\tau_{(1)}>\mathrm{s}\right) / \mathrm{P}\left(\tau_{(1)} \leq \mathrm{s}\right)$, depends on the distribution of $\tau_{(1)}$, which in turn depends on the joint distribution of $\left(\tau_{1}, \ldots, \tau_{\mathrm{p}}\right)$. The time of alarm is defined as

$$
t_{\mathrm{A}}=\min \mathrm{t}: \operatorname{LR}\left(\mathrm{m}_{\mathrm{s}}\right)>\mathrm{k}_{\mathrm{s}}
$$

\subsection{Three suggested methods for multivariate surveillance}

In this paper we compare results from three methods for multivariate surveillance; the T2 method (a reduction), a method for parallel surveillance and a simultaneous solution, derived from the optimal, full likelihood ratio.

\subsubsection{The T2 method}

An early multivariate method is the T2 method of Hotelling (1947). The statistic is assumed to have a known covariance matrix. The $\mathrm{T} 2$ is an example of a reduction. We assume that $\mathrm{X}$ and $\mathrm{Y}$ have the same distribution, conditional on $\tau_{\mathrm{X}}$ and $\tau_{\mathrm{Y}}$. Thus an alarm is given when

$$
\mathrm{T} 2(\mathrm{~s})=\frac{\left(x(s)-\mu^{D}(s)\right)^{2}}{\left(1-\rho^{2}\right) \sigma^{2}}+\frac{\left(y(s)-\mu^{D}(s)\right)^{2}}{\left(1-\rho^{2}\right) \sigma^{2}}-\frac{2 \rho\left(x(s)-\mu^{D}(s)\right)\left(y(s)-\mu^{D}(s)\right)}{\left(1-\rho^{2}\right) \sigma^{2}}>\mathrm{k} .
$$

URL: http://mc.manuscriptcentral.com/lssp 12 -mail: comstat@univmail.cis.mcmaster.ca 


\subsubsection{Parallel likelihood ratio systems}

The parallel surveillance system in this paper, denoted LRpar, is based on separate likelihood ratio systems for $\mathrm{X}$ and $\mathrm{Y}$. For $\mathrm{X}$ the likelihood ratio alarm statistic is

$$
\mathrm{LR}_{X}(\mathrm{~s})=\sum_{j=1}^{s} \frac{P(\tau=j)}{P(\tau \leq s)} \exp \left(\frac{\sum_{t=1}^{s}\left(x(t)-\mu^{D}(t)\right)^{2}}{2 \sigma^{2}}-\frac{\sum_{t=1}^{s}\left(x(t)-\mu^{C j}(t)\right)^{2}}{2 \sigma^{2}}\right)>k \frac{P\left(\tau_{X}>s\right)}{P\left(\tau_{X} \leq s\right)}
$$

where $\mu^{\mathrm{D}}$ and $\mu^{\mathrm{C}}$ are defined in (3) and $\tau$ is assumed to follow a geometric distribution with intensity $v$. The time of alarm for $\mathrm{X}$ is defined as

$$
\mathrm{t}_{\mathrm{AX}}=\min \left[\operatorname{LR}_{\mathrm{X}}(\mathrm{s})>\mathrm{k}_{\mathrm{s}}^{\mathrm{X}}\right]
$$

where $\mathrm{k}_{\mathrm{s}}^{\mathrm{X}}=\mathrm{k} \cdot\left(\mathrm{P} \tau_{\mathrm{X}}>\mathrm{s}\right) / \mathrm{P}\left(\tau_{\mathrm{X}} \leq \mathrm{s}\right)$. The $\mathrm{LR}_{\mathrm{Y}}(\mathrm{s})$ statistic and $\mathrm{t}_{\mathrm{AY}}$ are defined correspondingly. The time of alarm for the LRpar system is the first time for which either alarm system gives an alarm, i.e. $t_{A}=\min \left\{t_{A X}, t_{A Y}\right\}$. If $X$ and $Y$ are independent, the distribution of $t_{A}$ is a direct function of the distributions of $t_{\mathrm{AX}}$ and $\mathrm{t}_{\mathrm{AY}}$.

The two alarm limits, $\mathrm{k}_{\mathrm{s}}^{\mathrm{X}}$ and $\mathrm{k}_{\mathrm{s}}^{\mathrm{Y}}$, are adjusted to yield a specified false alarm property for the whole system. If there is no particular information regarding the cost for false alarms, then it is natural to have the same false alarm property for the two methods (e.g. equal $\mathrm{ARL}^{0}$ ). If inspection and restoration costs are not the same for the processes, Serel, et al. (2000) suggest different type I errors.

\subsubsection{Simultaneous solution using the joint likelihood ratio}

Recall from Section 4.1.3 that the optimal surveillance method for $C=\left\{\tau_{(1)} \leq s\right\}$ consists of s weighted partial likelihood ratios

$$
\sum_{t=1}^{s} w_{s}^{t} \cdot L(s, t)
$$

URL: http://mc.manuscriptcentral.com/lssp E-mail: comstat@univmail.cis.mcmaster.ca 
where $\mathrm{L}(\mathrm{s}, \mathrm{t})=\frac{f\left(m_{s} \mid \tau_{(1)}=t\right)}{f\left(m_{s} \mid \tau_{(1)}>s\right)}$

The event $\left\{\tau_{(1)}=\mathrm{t}\right\}$ consists of three sub-events:

$$
\begin{aligned}
& \left\{\tau_{X}=t \cap \tau_{Y}>t\right\}, \text { event } C D, \text { "a change in } X \text { at time } t " \\
& \left\{\tau_{X}>t \cap \tau_{Y}=t\right\}, \text { event DC, "a change in } Y \text { at time } t \text { " } \\
& \left\{\tau_{X}=t \cap \tau_{Y}=t\right\}, \text { event CC, "change in both } X \text { and } Y \text { at time } t \text { ". }
\end{aligned}
$$

Thus $\mathrm{w}_{\mathrm{s}}^{\mathrm{t}} \cdot \mathrm{L}(\mathrm{s}, \mathrm{t})$ is separated into $w_{s}^{t 0} \cdot L(s, t, C D)+w_{s}^{0 t} \cdot L(s, t, D C)+w_{s}^{t t} \cdot L(s, t, C C)=$

$$
w_{s}^{t 0} \cdot \frac{f\left(m_{s} \mid \tau_{X}=t, \tau_{Y}>t\right)}{f\left(m_{s} \mid \tau_{X}>t, \tau_{Y}>t\right)}+w_{s}^{0 t} \cdot \frac{f\left(m_{s} \mid \tau_{X}>t, \tau_{Y}=t\right)}{f\left(m_{s} \mid \tau_{X}>t, \tau_{Y}>t\right)}+w_{s}^{t t} \cdot \frac{f\left(m_{s} \mid \tau_{X}=t, \tau_{Y}=t\right)}{f\left(m_{s} \mid \tau_{X}>t, \tau_{Y}>t\right)}
$$

Since we want to detect changes in the $\mu$ vectors, the expression above is written as

$$
w_{s}^{j 0} \frac{f\left(x_{s}, y_{s} \mid \mu^{C t}, \mu^{D}\right)}{f\left(x_{s}, y_{s} \mid \mu^{D}, \mu^{D}\right)}+w_{s}^{0 t} \frac{f\left(x_{s}, y_{s} \mid \mu^{D}, \mu^{C t}\right)}{f\left(x_{s}, y_{s} \mid \mu^{D}, \mu^{D}\right)}+w_{s}^{t t} \frac{f\left(x_{s}, y_{s} \mid \mu^{C t}, \mu^{C t}\right)}{f\left(x_{s}, y_{s} \mid \mu^{D}, \mu^{D}\right)},
$$

where $f\left(x_{s}, y_{s}\right)$ is the bivariate normal distribution in (1) and (2). When $X$ and $Y$ are independent $\mathrm{X}$ and $\mathrm{Y}$, the expression above simplifies to

$$
w_{s}^{t 0} \frac{f\left(x_{s} \mid \tau_{X}=t\right)}{f\left(x_{s} \mid \tau_{X}>s\right)}+w_{s}^{0 t} \frac{f\left(y_{s} \mid \tau_{Y}=t\right)}{f\left(y_{s} \mid \tau_{Y}>s\right)}+w_{s}^{t t} \frac{f\left(x_{s} \mid \tau_{X}=t\right)}{f\left(x_{s} \mid \tau_{X}>s\right)} \cdot \frac{f\left(y_{s} \mid \tau_{Y}=t\right)}{f\left(y_{s} \mid \tau_{Y}>s\right)}
$$

where the first two components are those used in LRpar. The weights are

$$
w_{s}^{t 0}=\frac{P\left(\tau_{X}=t \cap \tau_{Y}>t\right)}{P\left(\tau_{(1)} \leq s\right)}, w_{s}^{0 t}=\frac{P\left(\tau_{X}>t \cap \tau_{Y}=t\right)}{P\left(\tau_{(1)} \leq s\right)}, w_{s}^{t t}=\frac{P\left(\tau_{1}=t \cap \tau_{2}=t\right)}{P\left(\tau_{(1)} \leq s\right)},
$$

where the bivariate distribution of $\left(\tau_{X}, \tau_{Y}\right)$ is governed by the intensity parameters $v_{1}, v_{.1}$ and $v_{11}$. The information regarding $\left(\tau_{\mathrm{X}}, \tau_{\mathrm{Y}}\right)$ is also included in the alarm limit, $\mathrm{k}_{\mathrm{s}}=\mathrm{k}^{\prime} \cdot \mathrm{P}\left(\tau_{(1)}>\mathrm{s}\right) / \mathrm{P}\left(\tau_{(1)} \leq \mathrm{s}\right)$, see Section 4.1.3.

URL: http://mc.manuscriptcentral.com/lssp E14-mail: comstat@univmail.cis.mcmaster.ca 


\subsubsection{Alarm regions for the three methods}

The methods T2, LRpar and LRjoint are made comparable by adjusting their respective alarm limits so that the probability of false alarm, PFA, equals 0.1 , where

$$
\mathrm{PFA}=\sum_{i=1}^{\infty} P\left(t_{A}<i\right) \cdot P\left(\tau_{(1)}=i\right)
$$

The alarm regions are illustrated in Figure 1, for different values of $\psi$ (correlation between the change times) and different values of $\rho$ (dependency between $\mathrm{X}$ and $\mathrm{Y}$ ).

<FIGURE 1>

For LRpar, an alarm is called if at least one of X or Y deviates largely from the D-state. For LRjoint (when $\mathrm{X}$ and $\mathrm{Y}$ are independent), an alarm is called when either $\mathrm{X}$ or $\mathrm{Y}$ or $(\mathrm{X}+\mathrm{Y})$ deviates from the D-state. The same holds for T2. For both LRjoint and T2, the shape of the alarm region changes as $\rho$ and $\psi$ changes, but not for LRpar.

\section{Results}

The methods (T2, LRpar and LRjoint) are made comparable by all having PFA=0.1, where PFA is summarized using the bivariate Geometric distribution that results in a specified $\psi$ (correlation between $\tau_{\mathrm{X}}$ and $\tau_{\mathrm{Y}}$ ).

LRpar and LRjoint have similar run length distributions (thus similar median run length, $\mathrm{MRL}^{0}$ ), whereas T2 has a higher $\mathrm{MRL}^{0}$, see Figure 2. For all methods, the run length distribution is similar for $\rho=0$ and $\rho=0.5$ (dependency between $\mathrm{X}$ and Y), but very different for $\psi=0$ versus $\psi=0.8$ (correlation between $\tau_{\mathrm{X}}$ and $\tau_{\mathrm{Y}}$ ). The density of $\tau_{(1)}$ is used to weight together the alarm times in PFA. As $\psi$ tends to 1 , the alarms tend to be more uniformly distributed and $\mathrm{MRL}^{0}$ is longer. For both $\mathrm{T} 2$ and LRpar, the alarm limit 
needs to be changed in order to maintain PFA $=0.10$ when a different density for $\tau_{(1)}$ is used. For LRjoint, the alarm statistic itself is changed when $\psi=0.8$, since the components CD, DC and CC are weighted differently.

$<$ FIGURE 2>

\subsection{Motivated alarms: the first change occurs immediately}

$\operatorname{CED}\left(\mathrm{t}_{1}, \mathrm{t}_{2}\right)$ is presented for $\tau_{(1)}=1$, i.e. when the first change occurs immediately. $<$ FIGURE 3>

\subsubsection{The effect of correlation between the change times}

The delay is shortest when both changes occur immediately $\left(\tau_{X}=\tau_{Y}=1\right)$, independent of $\psi$.

When independent change times are assumed $(\psi=0), \mathrm{T} 2$ has the shortest delay, but the three methods give similar delay. For the two likelihood ratio methods, the similarity was indicated by the similar alarm regions in Figure 1 . At $\left(\tau_{X}=\tau_{Y}=1\right)$, LRjoint has slightly shorter delay, compared to LRpar. LRjoint consists of three components $(\mathrm{CD}, \mathrm{DC}, \mathrm{CC}$, see section 4.2.2), whereas LRpar is based on two components (CD and DC).

When a positive correlation is assumed between the change times $(\psi=0.8)$, LRjoint is superior at $\left(\tau_{X}=\tau_{Y}=1\right)$. LRjoint assigns a large weight to the $\mathrm{CC}$ component and when the changes actually occur simultaneously, LRjoint has a short delay.

\subsubsection{The effect of the X-processes under surveillance being dependent}

For immediate changes in both processes $\left(\tau_{\mathrm{X}}=\tau_{\mathrm{Y}}=1\right)$, the $\mathrm{T} 2$ has the shortest delay and LRpar the longest, when $X$ and $Y$ are independent $(\rho=0)$. However, for $\rho=0.5$, LRpar has shortest delay and LRjoint longest. This is further discussed in 4.2.2.

URL: http://mc.manuscriptcentral.com/lssp 16-mail: comstat@univmail.cis.mcmaster.ca 


\subsection{Motivated alarms: the effect of the change times}

The delay $\operatorname{CED}\left(\mathrm{t}_{1}, \mathrm{t}_{2}\right)$ is presented for $\mathrm{t}_{1}=\{1,5,10\}$ and $\mathrm{t} 2=1,2, \ldots, 14$. $<$ FIGURE 4a>

$<$ FIGURE 4b $>$

$<$ FIGURE 4c>

\subsubsection{The effect of correlation between the change times}

For all methods, CED is longer when $\psi>0$. For LRpar, the delay is generally longer as a result of the higher alarm limit. The same holds for T2. Also for LRjoint, the delay is generally longer, but there is also a larger difference between $\operatorname{CED}(t, t)$ and $\operatorname{CED}(t, \infty)$, exemplified by $\operatorname{CED}(5,5)=3.5$ and $\operatorname{CED}(5,14)=4.2$. For $\psi>0$ the LRjoint works well when the changes do actually occur simultaneously.

Both for $\psi=0$ and $\psi=0.8$, simultaneous changes have shortest delay for all method, i.e. $\operatorname{CED}(\mathrm{t}, \mathrm{t})<\mathrm{CED}(\mathrm{t}, \mathrm{j}), \mathrm{j} \neq \mathrm{t}$. For $\mathrm{CED}(\mathrm{t}, \mathrm{t})$, both $\mathrm{X}$ and $\mathrm{Y}$ are in $\mathrm{C}$-state at each time point.

For the two LR methods, later changes have shortest delay (e.g. $\operatorname{CED}(1,1)>\operatorname{CED}(5,5))$, whereas T2 has the same delay for e.g $\left(\tau_{X}=\tau_{Y}=1\right)$ as for $\left(\tau_{X}=\tau_{Y}=5\right)$.

As one change time tends to infinity, the CED-curve depends only on the other change time $(\mathrm{CED}(\infty, \mathrm{t})$ depends only on $\mathrm{t})$.

\subsubsection{The effect of the processes under surveillance being dependent}

For LRpar the CED-curves are practically the same for $\rho=0$ and $\rho=0.5$.

For LRjoint, the simultaneous change situation, $\tau_{X}=\tau_{Y}$, is quicker detected if the processes are independent. The same holds for $\mathrm{T} 2$.

For T2, the CED-curve only depends on the distance $\left(t_{1}-t_{2}\right)$, see Andersson (2008).

URL: http://mc.manuscriptcentral.com/Issp E-mail: comstat@univmail.cis.mcmaster.ca 
Both for $\rho=0$ and for $\rho=0.5$, T2 has longer CED than both the LR methods, in most situations.

For $\rho=0$, LRpar and LRjoint have similar CED-curves. For $\rho=0.5$, LRpar has a shorter delay for simultaneous changes $\left(\tau_{X}=\tau_{Y}\right)$, compared to LRjoint, Figure $4 \mathrm{a}-4 \mathrm{c}$. One reason for the long delay of LRjoint is the assumption that $\psi=0$. Another was pointed out in Wessman (1999) who investigated multivariate surveillance for the situation $C=\left\{\tau_{(1)}=s\right\}$ and showed that if changes occur in all processes, the probability of detecting it is lower if the observations are highly correlated.

For $\rho=0$, the $\operatorname{CED}(t, t)$ is much smaller than $\operatorname{CED}(t, \infty)$ for all three methods. But for $\rho=0.5$, when we use LRjoint or $T 2$, the $\operatorname{CED}(t, t)$ is approximately the same as $\operatorname{CED}(t, \infty)$, exemplified for $\operatorname{LRjoint~by~} \operatorname{CED}(5,5)=3.3$ and $\operatorname{CED}(5,14)=3.3$.

When $\rho=0.5$, both LRjoint and T2 yield long delay for "almost simultaneous changes", so that $\operatorname{CED}(t,|t-1|)>\operatorname{CED}(t, \infty)$, see Figure $4 b$ and $4 c$ (exemplified for LRjoint by $\operatorname{CED}(5,6)=3.5$ and $\operatorname{CED}(5,14)=3.3)$. Consider $\mathrm{T} 2$, based on the Mahalanobis distance $\mathrm{M}_{\tau \mathrm{X}, \tau \mathrm{Y}}(\mathrm{t})=\left(X^{\prime}(t)\right)^{2}+\left(Y^{\prime}(t)\right)^{2}-2 \rho\left(X^{\prime}(t)\right)\left(Y^{\prime}(t)\right)$. In a simple shift situation $(0$ to $\theta)$ with simultaneous changes, we have

$$
E\left[M_{\tau X, \tau Y}(t)\right]=\theta^{2}(2-2 \rho) \text {, for all values of } t \text {. }
$$

When $\tau_{X} \neq \tau_{Y}$, we have

$$
\begin{aligned}
& E\left[M_{\tau X, \tau Y}(t)\right]=\theta^{2}, \text { for } \tau_{(1)} \leq t<\tau_{(2)} \\
& E\left[M_{\tau X, \tau Y}(t)\right]=\theta^{2}(2-2 \rho), \text { for } t \geq \tau_{(2)}
\end{aligned}
$$

URL: http://mc.manuscriptcentral.com/lssp 18-mail: comstat@univmail.cis.mcmaster.ca 
This makes $E\left[M_{i, i}(t)\right]$ smaller than (or equal to) $E\left[M_{i, j}(t)\right]$, when $\rho$ is close to 1 , indicating longer delay for simultaneous changes. In this simulation study, however, the change is from a constant level to an increasing function, making the expressions more complex. For $\rho$ close to 1, we again find smaller values for $E\left[M_{i, i}(t)\right]$ than for $E\left[M_{i, j}(t)\right]$, indicating a long delay for simultaneous changes (and vice versa for $\rho$ close to 0 ). But for $\rho=0.5$ the values of $E[\mathrm{Mi}, \mathrm{j}(\mathrm{t})]$ for different $\mathrm{t}$ are not necessarily monotone as a function of $\tau_{X}-\tau_{Y}$ and this causes the non-monotonic CED-function (for T2 we have $\operatorname{CED}(10,5)=$

\section{1, $\operatorname{CED}(10,9)=4.3, \operatorname{CED}(10,10)=4.0)$.}

\section{Discussion}

Warning systems are used in many areas: public health, bio terrorism, radiation, pregnancy, intensive care patients. Very often, several processes can be used to detect an underlying change. Then we need a warning (or surveillance) system for multivariate data. When monitoring more than one process, we must consider the dependency between the processes and the correlation between the change times. Surveillance of autocorrelated processes is an important area, though not treated in this paper.

Three methods of multivariate surveillance are compared. In the Hotellings T2 the multivariate data is reduced to a scalar at each time point. In the LRpar method, the likelihood ratio method is applied to each marginal process. The LRjoint method is optimal according to the Shiryaev criterion and is derived from the joint likelihood ratio.

The alarm limits of each of the three systems are adjusted to yield the same false alarm probability.

We investigate the effect of a positive correlation between the change times (the correlation between $\tau_{X}$ and $\tau_{Y}$ is denoted $\psi$ ). We also investigate the effect of a positive 
covariance between the processes $(\mathrm{X}$ and $\mathrm{Y})$, conditional on $\tau_{\mathrm{X}}$ and $\tau_{\mathrm{Y}}$ (the covariance is denoted $\rho$ ). The LRjoint is the only method that uses the information of $\psi$ in the alarm statistic. Both T2 and LRjoint incorporate the information of $\rho$.

The evaluation is made using the delay of an alarm, in relation to the first change time.

The methods are first compared for independent change times $(\psi=0)$. For immediate changes in both processes $\left(\tau_{\mathrm{X}}=\tau_{\mathrm{Y}}=1\right), \mathrm{T} 2$ has the shortest delay, followed by LRjoint and then LRpar. T2 allocates the alarms early, whereas the two LR methods have few early alarms. LRjoint has a slightly shorter delay than LRpar, since LRjoint includes three components, corresponding to a change in either X or Y or both, whereas LRpar includes only two components (change in either $\mathrm{X}$ or $\mathrm{Y}$ ) which is not optimal for simultaneous changes. However, the difference is small since $\psi=0$ (we do not expect many simultaneous changes). For later simultaneous changes $\left(\tau_{\mathrm{X}}=\tau_{\mathrm{Y}}\right)$, LRjoint is slightly better than LRpar, whereas T2 here yields a long delay. T2 allocates the alarms early and also T2 uses only observations from the current time point, thus it is not based on more data at later time points (as opposed to the LR methods). The T2 use of only the observations at the current time point corresponds to the Shewhart method in univariate surveillance. T2 is a reduction, which is sufficient at simultaneous change times, but the method is not always optimal for $\tau_{X}=\tau_{Y}$. For different change times $\left(\tau_{X} \neq \tau_{Y}\right)$, LRpar has the same delay as LRjoint and T2 has the longest delay, because of the alarm allocation.

Next we investigate the effect of a positive correlation between the change times $(\psi=0.8)$. For $\tau_{X}=\tau_{Y}=1$, LRjoint has the shortest delay, followed by T2 and then LRpar. LRjoint uses the information that the change times are likely to occur simultaneously and $\mathrm{T} 2$ benefits from allocating the alarm early. For $\tau_{X}=\tau_{Y}=t, t>1$, LRjoint has the shortest 
delay, followed by LRpar and then T2. As for $\psi=0$, T2 only works well for early simultaneous changes. For $\tau_{X} \neq \tau_{Y}$, LRpar gives slightly shorter delay than LRjoint, and T2 gives the longest delay. LRjoint uses the information that $\psi>0$, which is a disadvantage when the changes actually do occur at different times.

We also compare the methods in the situation when $\mathrm{X}$ and $\mathrm{Y}$ have a positive covariance $(\rho=0.5)$. For $\tau_{X}=\tau_{Y}=1$, LRpar has the shortest delay, followed by T2 and then LRjoint. For $\tau_{X}=\tau_{Y}=t, t>1$, LRpar gives shorter delay than LRjoint (although LRjoint now works better than T2). For LRjoint, one reason for the long delay for $\tau_{X}=\tau_{Y}$ is the assumption of $\psi=0$, which results in a low weight for the "simultaneous change component". Both T2 and LRjoint do include the components of the Mahalanobis distance, which tend to be smaller for simultaneous changes when $\rho$ is large, see Wessman (1999). If $\mathrm{X}$ and $\mathrm{Y}$ are independent and change simultaneously, this is a stronger indication than if they change simultaneously when they are positively dependent and thus the delay is shorter in the independent situation. The values of the Mahalanobis distance depends on the type of change (here we have a change from a constant level to an increasing function) as well as $\rho$. In a simple situation with a shift, the Mahalanobis distance $(\mathrm{M})$ is a monotone function of the distance between the change times: for $\rho$ close to 0 , the delay will be shortest for simultaneous changes and for $\rho$ close to 1 the delay will be longest for simultaneous changes. This also holds for a more complex change, but for $\rho=0.5$ (which was investigated here) the association is not so clear-cut, which results in a non-monotonic delay curve.

In this paper we only deal with positive dependency. A negative correlation between the change times, $\psi<0$, implies that the change times do not coincide. Then it would be 
best to have a very small weight for the component for simultaneous changes. If the processes themselves have a negative covariance $(\rho<0)$, the implication is that $\mathrm{X}=-\mathrm{Y}$. Then the alarm region would constitute of large values of $(\mathrm{X}+\mathrm{Y})$ and the alarm region for $\rho<0$ would be similar to that of a positive correlation between the change times $(\psi>0)$.

\section{References}

Abu-Shawiesh M;Abdullah M. A new robust bivariate control chart for location. Communications in Statistics-Simulation and Computation, 2001, 30, (3), 513-530.

Andersson E. The impact of intensity in surveillance of cyclical processes. Communications in Statistics-Simulation and Computation, 2004, 33, (4), 889-913.

Andersson E. Hotelling's T2 method in multivariate on-line surveillance. On the delay of an alarm. Research report: Statistical Research Unit, Göteborg University, Sweden, 2008.

Andersson E;Bock D;Frisén M. Detection of turning points in business cycles. Journal of Business Cycle Measurement and Analysis, 2004, 1, (1), 93-108.

Aparisi F;Jabaloyes J;Carrión A. Generalized variance chart design with adaptive sample sizes. The bivariate case. Communications in Statistics-Simulation and Computation, 2001, 30, (4), 931-949.

Baron M. Bayes and asymptotically pointwise optimal stopping rules for the detection of influenza epidemics. Case Studies in Bayesian Statistics, vol 6; Gatsonis C, Kass RE, Carriquiry A, et al., Eds.; Springer-Verlag: New York, 2002; 153-163.

Bock D. Aspects on the control of false alarms in statistical surveillance and the impact on the return of financial decision systems. Journal of Applied Statistics, 2008, 35, (2), $213-227$.

Bodden KM;Rigdon SE. A program for approximating the in-control ARL for the MEWMA chart. Journal of Quality Technology, 1999, 31, (1), 120-123.

Cheng AY;Liu RY. Monitoring multivariate aviation safety data by data depth: Control charts and threshold systems. IIE Transactions, 2000, 32, (9), 861-872.

Crosier RB. Multivariat Generalizations of Cumulative Sum Quality-Control Schemes. Technometrics, 1988, 30, 291-303. 
Does RJMM;Roes KCB;Trip A. Handling multivariate problems with univariate control charts. Journal of Chemometrics, 1999, 13, (3-4), 353-369.

Frisén M. Statistical surveillance. Optimality and methods. International Statistical Review, 2003, 71, (2), 403-434.

Frisén M. Financial surveillance. Wiley, 2007272.

Frisén M;de Maré J. Optimal Surveillance. Biometrika, 1991, 78, 271-80.

Frisén M;Sonesson C. Optimal surveillance. Spatial surveillance for public health Lawson A, Kleinman K, Eds.; Wiley, 2005; 31-57.

Frisén M;Sonesson C. Optimal surveillance based on exponentially weighted moving averages. Sequential analysis, 2006, 25, (4), 379-403.

Frisén M;Wessman P. Evaluations of likelihood ratio methods for surveillance.

Differences and robustness. Communications in Statistics-Simulations and Computations, 1999, 28, (3), 597-622.

Gan FF. Joint monitoring of process mean and variance. Nonlinear Analysis, 1997, 30, (7), 4017-4024.

Guerrero-Cusumano J-L. Testing variability in multivariate quality control: A conditional entropy measure approach. Information Sciences, 1995, 86, (1-3), 179-202.

Hamilton JD. A new approach to the economic analysis of nonstationary time series and the business cycle. Econometrica, 1989, 57, 357-384.

Hawkins DM. Multivariate Quality Control Based on Regression-Adjusted Variables. Technometrics, 1991, 33, 61-75.

Hotelling H. Multivariate Quality Control. Techniques of statistical analysis Eisenhart C, Hastay MW, Wallis WA, Eds.; McGraw-Hill: New York, 1947.

Javaheri A;Houshmand AA. Average run length comparison of multivariate control charts. Journal of Statistical Computation and Simulation, 2001, 69, (2), 125-140.

Jolayemi JK. A model for the statistical design of multivariate control charts with multiple control regions. Applied Mathematics and Computation, 2000, 109, (1), 73 91.

Järpe E. Surveillance of spatial patterns. Communications in Statistics. Theory and Methods, 1999, 28, 3009-3025. 
Kang L;Albin SL. On-line monitoring when the process yields a linear profile. Journal of Quality Technology, 2000, 32, (4), 418-426.

Knoth S;Schmid W. Control charts for time series: a review. Frontiers in statistical quality control, vol 7; Lenz H-J, Wilrich P-T, Eds.; Physica: Heidelberg, 2004; 210236.

Koskinen L;Öller L-E. A Classifying Procedure for Signalling Turning Points. Journal of Forecasting, 2004, 23, (3), 197-214.

Love TE;Linderman K. A Weibull process failure mechanism for the economic design of MEWMA control charts. Journal of Statistical Computation and Simulation, 2003, $73,(3), 195-202$.

Lowry CA;Woodall WH;Champ CW;Rigdon SE. A multivariate exponentially weighted moving average control chart. Technometrics, 1992, 34, 46-53.

Lu XS;Xie M;Goh TN;Lai CD. Control chart for multivariate attribute processes. International Journal of Production Research, 1998, 36, (12), 3477-3489.

Löfqvist C;Andersson E;Sigurdsson J, et al. Longitudinal Postnatal Weight and Insulinlike Growth Factor I Measurements in the Prediction of Retinopathy of Prematurity. Archives of Ophthalmology, 2006, 124, 1711-1718.

Marshall AW;Olkin I. A new method for adding a parameter to a family of distributions with application to the exponential and Weibull families. Biometrika, 1997, 84, (3), 641-652.

Mason RL;Chou YM;Sullivan JH;Stoumbos ZG;Young JC. Systematic patterns in T-2 charts. Journal of Quality Technology, 2003, 35, (1), 47-58.

Mason RL;Tracy ND; Young JC. Decomposition of T2 for multivariate control chart interpretation. Journal of Quality Technology, 1995, 27, (2), 99-108.

Molnau WE;Runger GC;Montgomery DC;Skinner KR;Loredo EN;Prabhu SS. A program for ARL calculation for multivariate EWMA charts. Journal of Quality Technology, 2001, 33, (4), 515-521.

Neftci S. Optimal prediction of cyclical downturns. Journal of Economic Dynamics and Control, 1982, 4, 225-41.

Okhrin Y;Schmid W. Surveillance of univariate and multivariate linear time series. Financial surveillance Frisén M, Ed. Wiley: Chichester, 2007. 
Page ES. Continuous inspection schemes. Biometrika, 1954, 41, 100-114.

Petzold M;Sonesson C;Bergman E;Kieler H. Surveillance in longitudinal models.

Detection of intra-uterine growth restriction. Biometrics, 2004, 60, (4), 1025-1033.

Pignatiello JJ;Runger GC. Comparisons of Multivariate CUSUM Charts. Journal of Quality Technology, 1990, 22, 173-186.

Qiu PH;Hawkins D. A rank-based multivariate CUSUM procedure. Technometrics, 2001, 43, (2), 120-132.

Roberts SW. Control Chart Tests Based on Geometric Moving Averages. Technometrics, 1959, $1,239-250$.

Royston P. Identifying the fertile phase of the human menstrual cycle. Statistics in Medicine, 1991, 10, 221-240.

Runger GC;Keats JB;Montgomery DC;Scranton RD. Improving the performance of the multivariate exponentially weighted moving average control chart. Quality and Reliability Engineering Internato, 1999, 15, (3), 161-166.

Sepúlveda A;Nachlas JA. A simulation approach to multivariate quality control. Computers \& Industrial Engineering, 1997, 33, (1-2), 113-116.

Serel DA;Moskowitz H;Tang J. Univariate (X)over-bar control charts for individual characteristics in a multinormal model. Iie Transactions, 2000, 32, (12), 1115-1125.

Shewhart WA. Economic Control of Quality of Manufactured Product. MacMillan and Co., 1931.

Shiryaev AN. On optimum methods in quickest detection problems. Theory of Probability and its Applications., 1963, 8, 22-46.

Sonesson C;Frisén M. Multivariate surveillance. Spatial surveillance for public health Lawson A, Kleinman K, Eds.; Wiley, 2005.

Stoumbos ZG;Jones LA. On the properties and design of individuals control charts based on simplicial depth. Nonlinear Studies, 2000, 7, (2), 147-178.

Stoumbos ZG;Sullivan JH. Robustness to non-normality of the multivariate EWMA control chart. Journal of Quality Technology, 2002, 34, (3), 260-276.

Sun K;Basu AP. A characterization of a bivariate geometric distribution. Statistics \& Probability Letters, 1995, 23, 307-311. 
Talluri S;Sarkis J. A methodology for monitoring system performance. International Journal of Production Research, 2002, 40, (7), 1567-1582.

Wessman P. Some Principles for surveillance adopted for multivariate processes with a common change point. Communications in Statistics. Theory and Methods, 1998, 27, 1143-1161.

Wessman P. The surveillance of several processes with different change points. Research report \# 1999:2: Department of Statistics, Göteborg University, Sweden, 1999.

Wikström C;Albano C;Eriksson L, et al. Multivariate process and quality monitoring applied to an electrolysis process: Part I. Process supervision with multivariate control charts. Chemometrics and Intelligent Laboratory Systems, 1998, 42, (1-2), 221-231.

Wong WK;Moore A;Cooper G;Wagner M. WSARE: What's Strange about Recent Events? Journal of Urban Health, 2003, 80, i66-i75.

Woodall WH;Ncube MM. Multivariate Cusum Quality Control Procedures. Technometrics, 1985, 27, 285-292.

Yumin L. An improvement for mewma in multivariate process control*1. Computers \& Industrial Engineering, 1996, 31, (3-4), 779-781. 


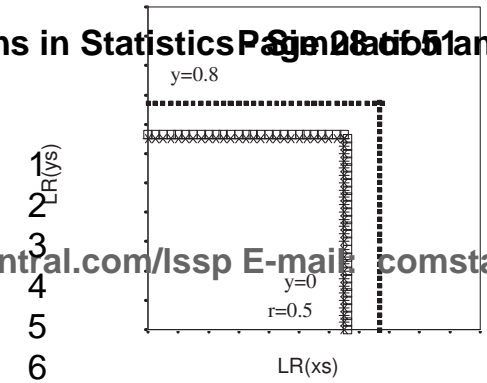




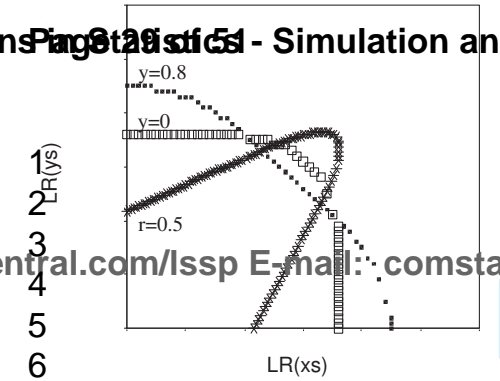




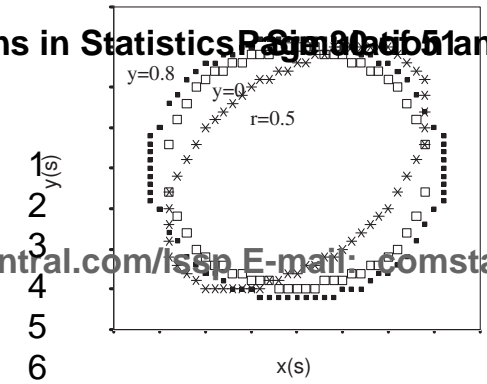




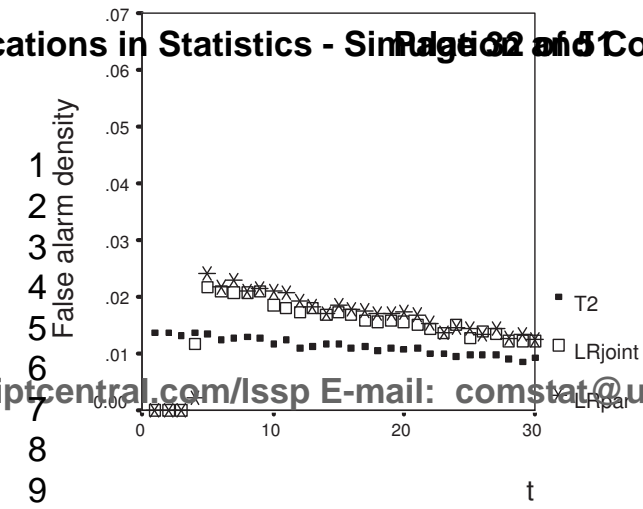




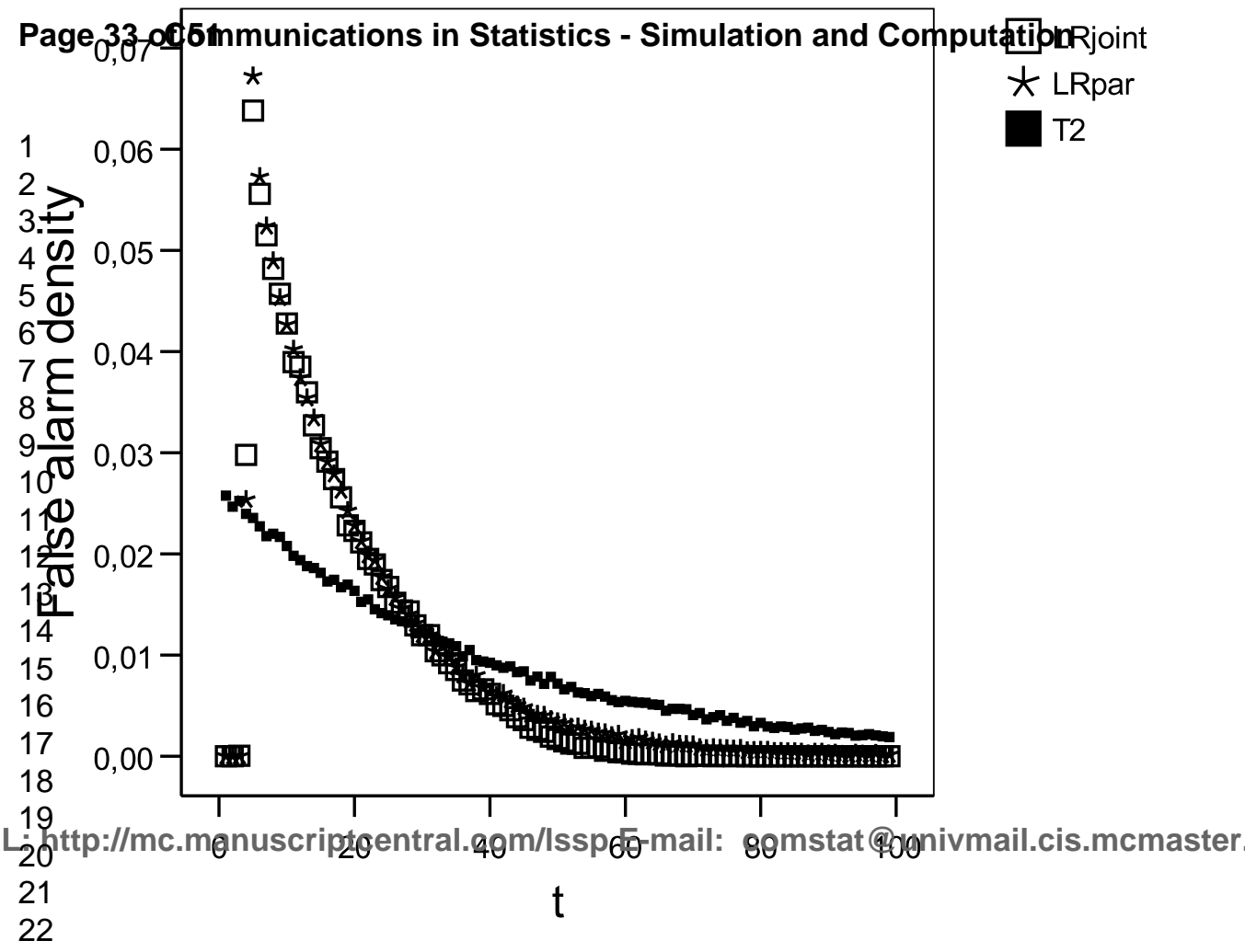




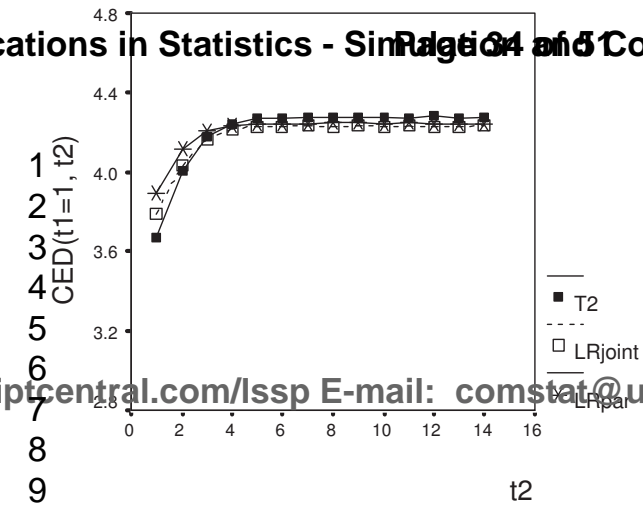




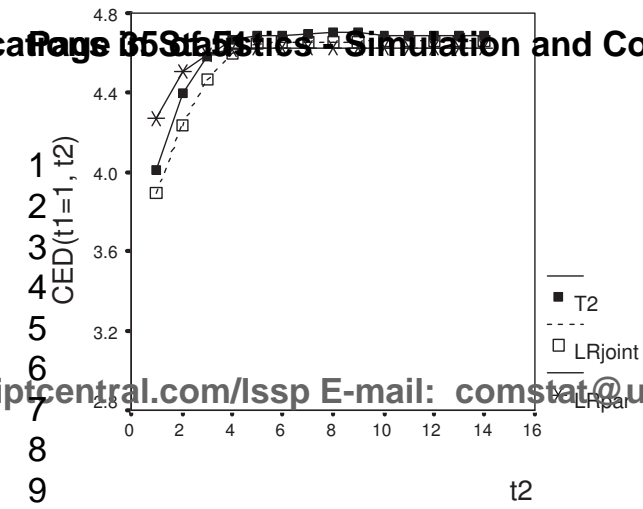




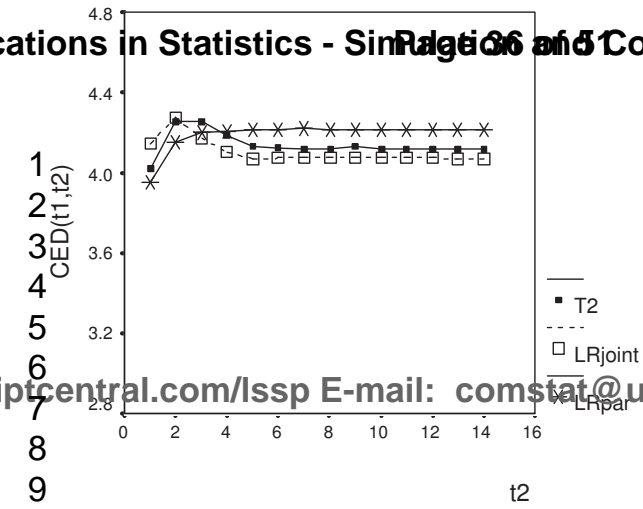




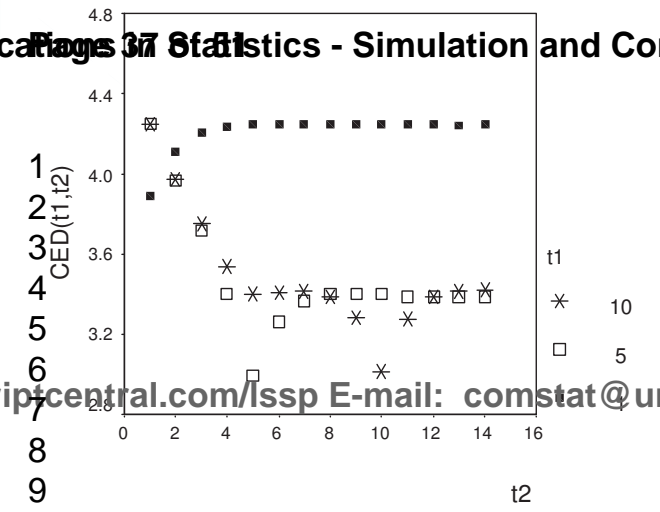




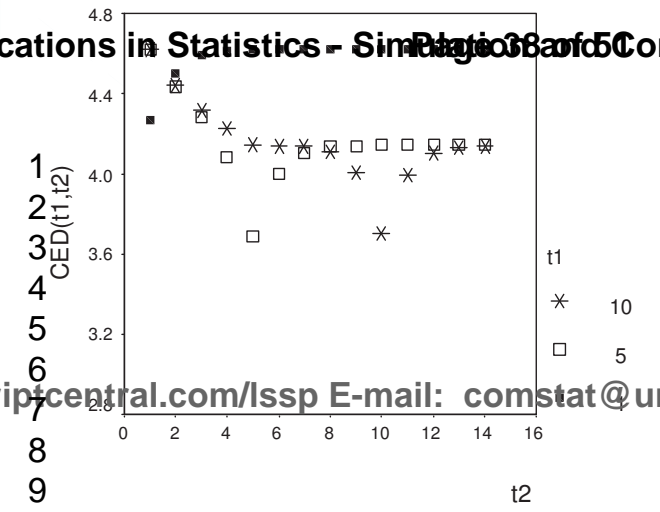




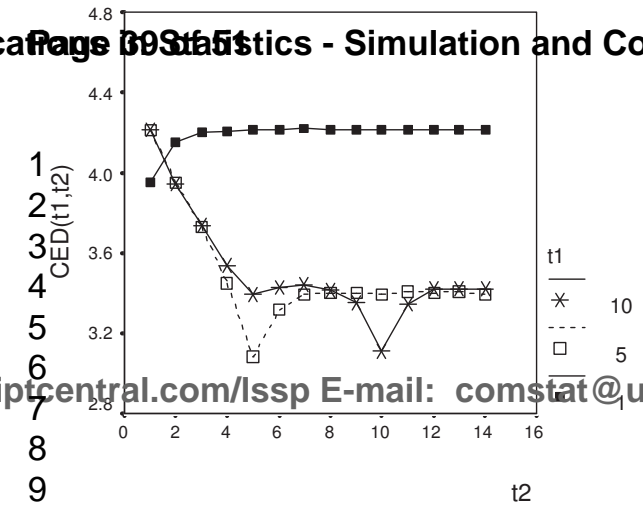




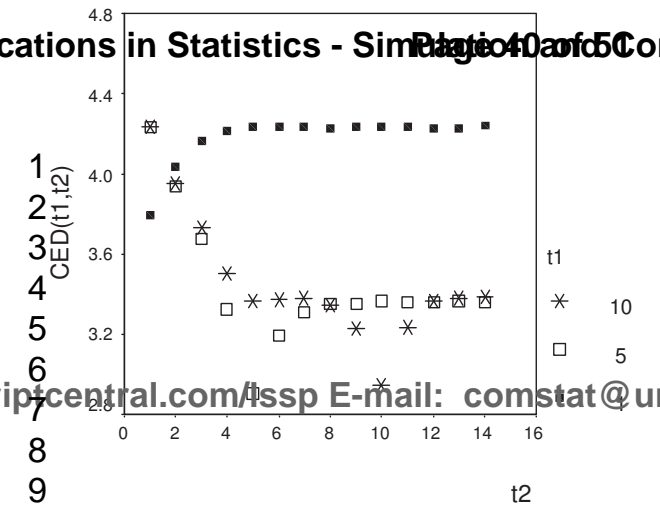




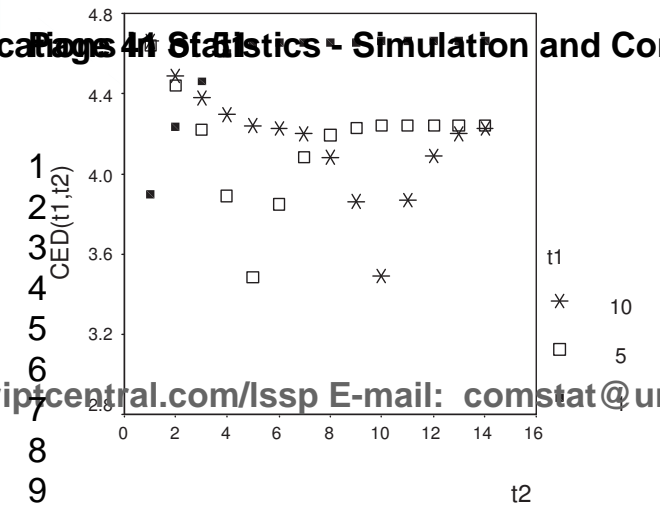




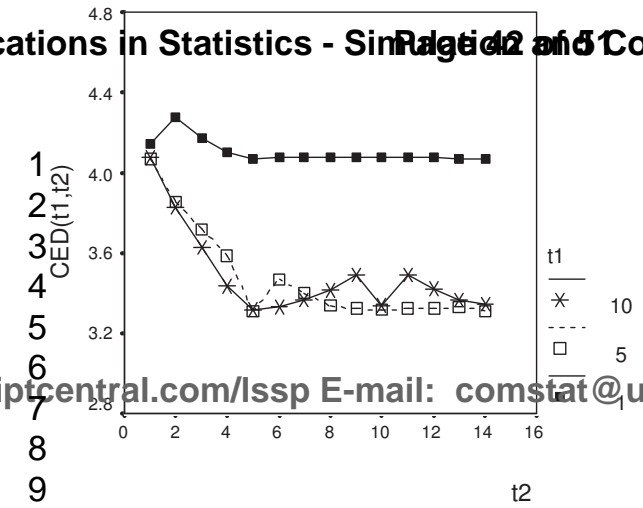




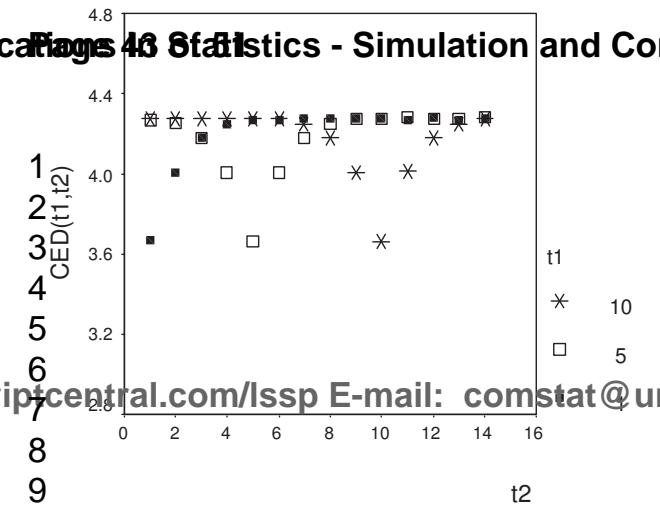




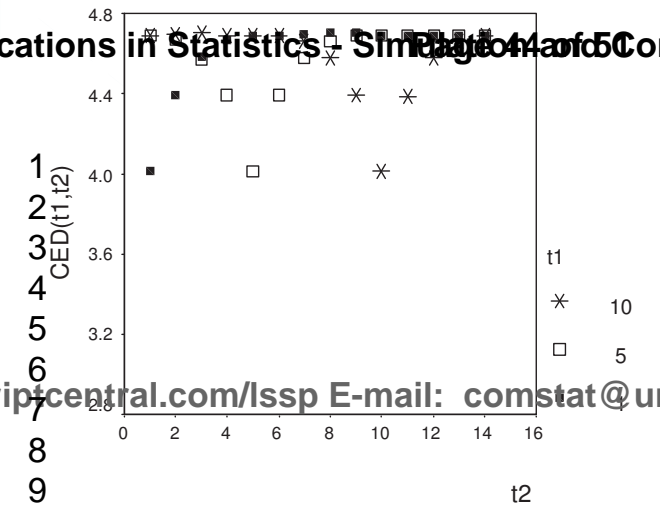




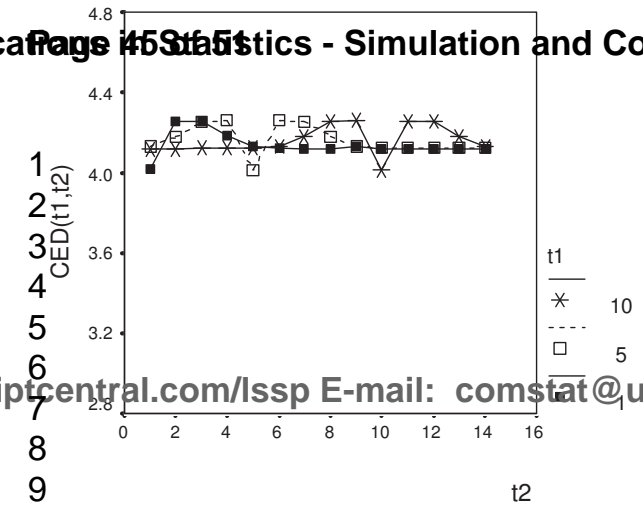


Figures and legends to figures
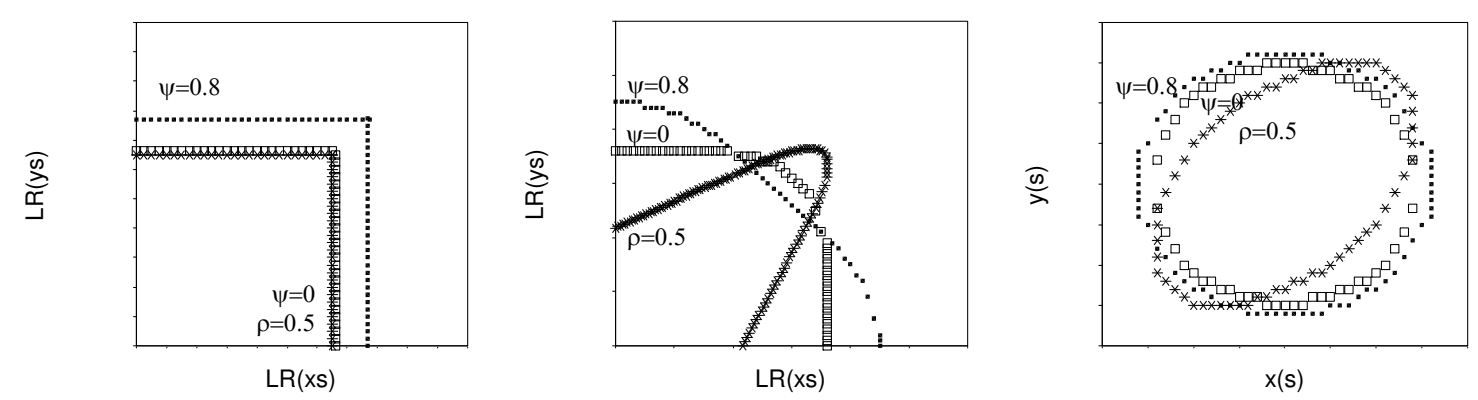

Figure 1: Alarm limit for LRpar (left), LRjoint (middel), T2 (right). Open square for $\{\psi=0, \rho=0\}$, filled square for $\{\psi=0.8, \rho=0\}$, star for $\{\rho=0.5, \psi=0\}$. 

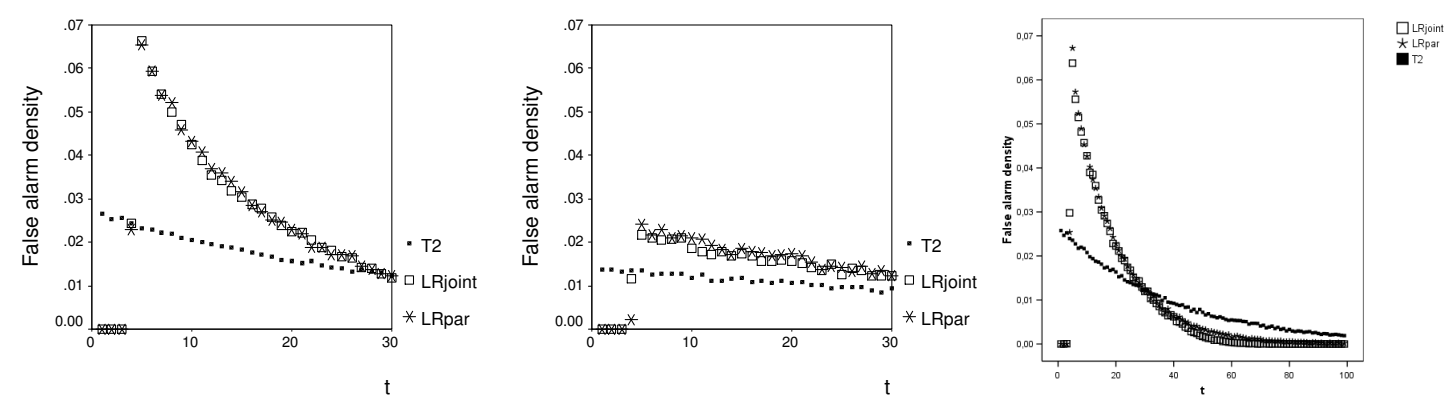

Figure 2: False alarm density, $P\left(t_{A}=t\right)$. Left: $\psi=0$, middle: $\psi=0.8$, right: $\rho=0.5$.

15

16

17

18

19

20

21

22

23

24

25

26

27

28

29

30

31

32

33

34

35

36

37

38

39

40

41

42

43

44

45

46

47

48

49

50

51

52

53

54

55

56

57

58

59

60

URL: http://mc.manuscriptcentral.com/Issp E-mail: comstat@univmail.cis.mcmaster.ca 



Figure 3: Conditional expected delay $C E D\left(t_{1}, t_{2}\right)$. Left: $\psi=0$, middle: $\psi=0.8$, right $\rho=0.5$. 
1

2

3

4

5

6

7

8

9

10

11

12

13

14

15

16

17

18

19

20

21

22

23

24

25

26

27

28

29

30

31

32

33

34

35

36

37

38

39

40

41

42

43

44

45

46

47

48

49

50

51

52

53

54

55

56

57

58

59

60
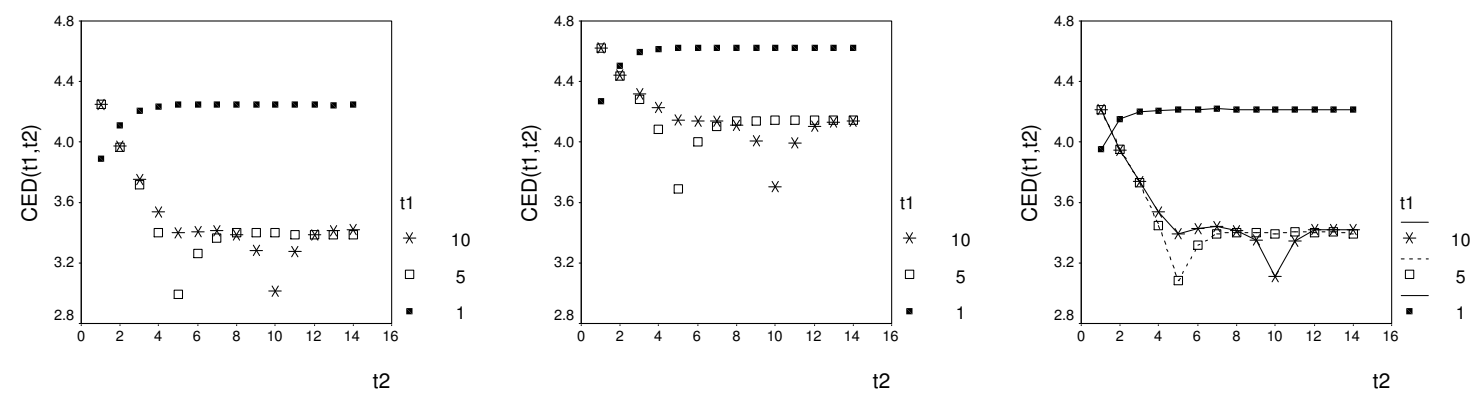

Figure 4a: Conditional expected delay, $C E D\left(t_{1}, t_{2}\right)$ for LRpar, $t_{1}=\{1,5,10\}$. Left: $\psi=0$, middle: $\psi=0.8$, right $\rho=0.5$. 

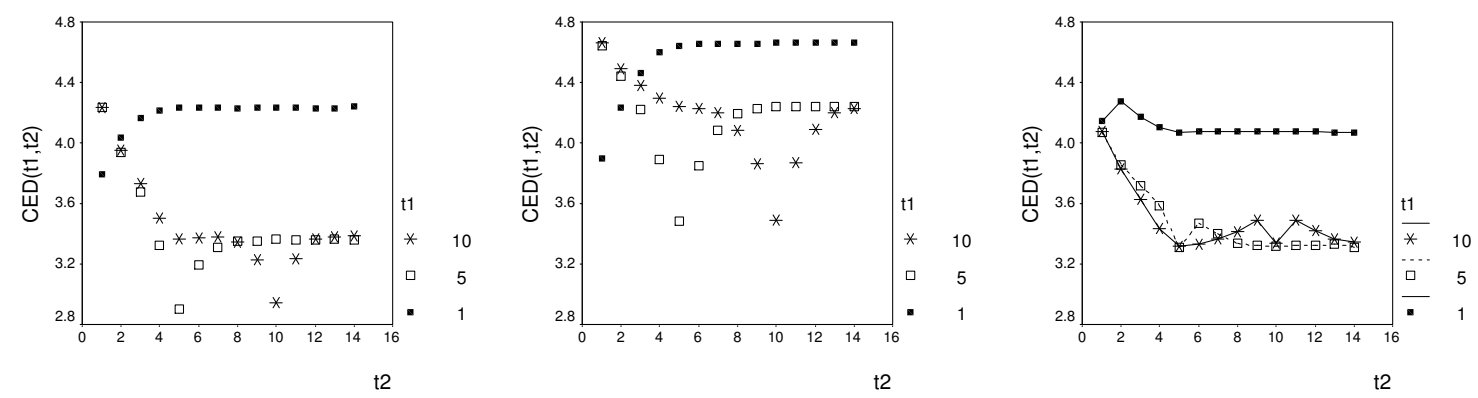

Figure 4b: Conditional expected delay, $C E D\left(t_{1}, t_{2}\right)$ for LRjoint, $t_{1}=\{1,5,10\}$. Left: $\psi=0$, middle: $\psi=0.8$, right $\rho=0.5$. 
1

2

3

4

5

6

7

8

9

10

11

12

13

14

15

16

17

18

19

20

21

22

23

24

25

26

27

28

29

30

31

32

33

34

35

36

37

38

39

40

41

42

43

44

45

46

47

48

49

50

51

52

53

54

55

56

57

58

59

60
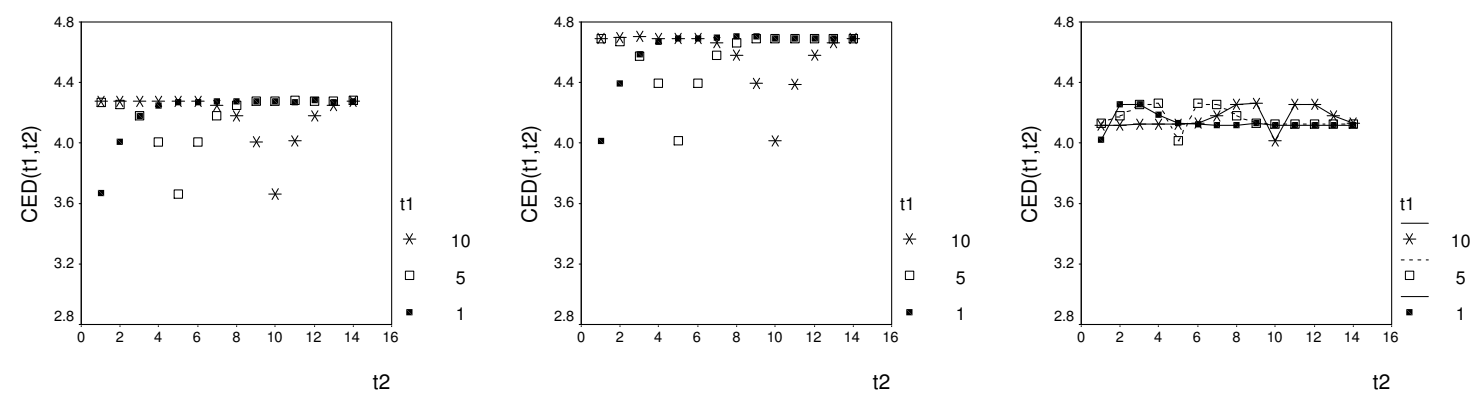

Figure 4c: Conditional expected delay, $C E D\left(t_{1}, t_{2}\right)$ for $T 2, t_{1}=\{1,5,10\}$. Left: $\psi=0$, middle: $\psi=0.8$, right $\rho=0.5$. 